\title{
北極徒歩探検によって観測された海水上の雪の安定同位体比
}

\author{
一柳 錦平 $* 1, * 3 \cdot$ 荻田 泰永 $* 2 \cdot$ 田上 雅浩 $* 1$
}

\section{Stable isotopes in snow on sea ice observed by the Arctic expedition on foot}

\author{
Kimpei ICHIYANAGI*1,*3, Yasunaga OGITA*2 and Masahiro TANOUE*1
}

\begin{abstract}
Stable isotopes in snow on sea ice were observed in the Canadian Arctic Sea. Twenty-three snowpack and four new snow samples were collected along the length of expedition on foot from March to May in 2011. Stable isotopes in snow ranged from -25 to $-35 \%$ in $\delta^{18} \mathrm{O}$ and from 3 to $13 \%$ in d-excess, and the local meteoric water line (LMWL) is $\delta \mathrm{D}=8.4^{*} \delta{ }^{18} \mathrm{O}+18.7$. There are no relationships between $\delta{ }^{18} \mathrm{O}$ in snow and surface air temperature in this study. Temporal variation of $\delta^{18} \mathrm{O}$ in snow is influenced by the direction of moisture flux, low (high) $\delta^{18} \mathrm{O}$ in snow exists when southwesterly (northerly or easterly) moisture flux dominants.
\end{abstract}

Key words: stable isotopes in snow, sea ice, Canadian Arctic Sea, Arctic expedition on foot

\section{1. はじめに}

降水の安定同位体比 $\left(\delta^{18} \mathrm{O}, \delta \mathrm{D}\right)$ は, International Atomic Energy Agency/Global Network of Isotopes in Precipitation (IAEA/GNIP) によっ て世界各地で観測されており，南極やグリーンラ ンドでは地上気温との間によい相関があること が観測されている (Rozanski et al., 1993)。また, 雪水コアなどの $\delta{ }^{18} \mathrm{O}$ は古気候の復元によく利用 されている (Ichiyanagi, 2007; Miller et al., 2010)。 しかし, 北極圈での降水の安定同位体比の観測は 多くなく, とくに海水上での観測はアクセスが困 難なため非常に少ない。近年の地球温暖化によっ て 2007 年や 2011 年は北極圈の海水面積が最小記 録となり (Ogi and Wallace, 2012)，今後さらに温 暖化が進めば海水上での観測自体ができなくなる
可能性もある。

そこで本研究では, 著者の一人である荻田が カナダ北極圈を徒歩で冒険する際に, 海水上の雪 のサンプリングを実施した（2011 年の北極探検 の様子は, http://www.ogita-exp.com/homepage/ 2011tabi.html を参照)。このように貴重な雪サン プルの安定同位体比を分析し，その変動要因につ いて地上気温と大気再解析データより考察する。

\section{2. 研究地域と研究方法}

海水上の雪サンプルは, カナダ北極圈多島海 地域の Resolute $\left(74.73^{\circ} \mathrm{N}, 95.20^{\circ} \mathrm{W}\right)$ から Gjoa Haven $\left(68.42^{\circ} \mathrm{N}, 96.30^{\circ} \mathrm{W}\right)$ までの $1,046 \mathrm{~km}$ を 徒歩で探検する際に (Photo 1), 27 地点におい て積雪表層部の雪を, 4 地点に打いてソリに積

* 1 熊本大学大学院自然科学研究科 Graduate School of Science and Technology, Kumamoto University

* 2 荻田泰永北極点事務局 Yasunaga Ogita North Pole office

* 3 海洋研究開発機構, 地球環境变動領域 Research Institute for Global Change, Japan Agency for Marine-Earth Science and Technology 
もった新雪を $20 \mathrm{ml}$ のポリボトルに詰めて採取し た（Table 1)。生死にかかわる冒険のため，時間 や労力のかかる積雪深は測定していない。採取 期間は 2011 年 3 月 16 日から 5 月 12 日までであ る。雪サンプルの $\delta{ }^{18} \mathrm{O}$ および $\delta \mathrm{D}$ は, 熊本大学 自然科学研究科の同位体質量分析装置 (Delta-V)

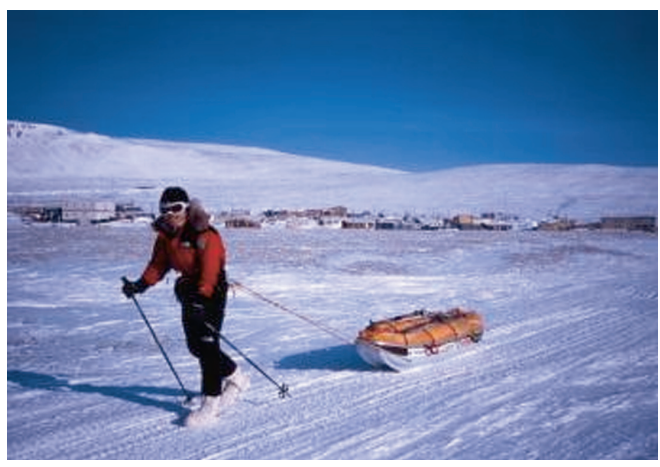

Photo 1. Arctic expedition on foot. (a) $\delta^{18} \mathrm{O}$ in Snow

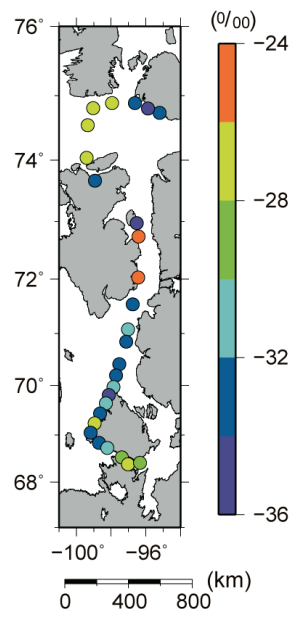

(b) d-excess in Snow

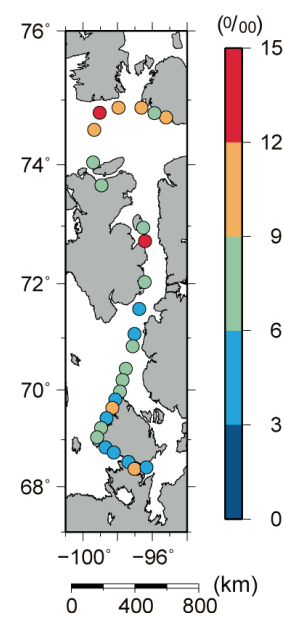

Fig. 1. Distributions of $\delta^{18} \mathrm{O}$ (a) and d-excess (b) in snow along the expedition from Resolute to Gjoa Haven in Canadian Arctic Sea.

Table 1. Summary of snow sampling observed in this study.

\begin{tabular}{|c|c|c|c|c|c|c|c|c|}
\hline No. & Date & $\begin{array}{c}\text { Latitude } \\
\left({ }^{\circ} \mathrm{N}\right)\end{array}$ & $\begin{array}{c}\text { Longitude } \\
\left({ }^{\circ} \mathrm{W}\right)\end{array}$ & $\begin{array}{l}\text { Temp. } \\
\left({ }^{\circ} \mathrm{C}\right)\end{array}$ & $\begin{array}{c}\text { Type of } \\
\text { snow }\end{array}$ & $\begin{array}{l}\delta \mathrm{D} \\
(\%)\end{array}$ & $\begin{array}{l}\delta^{18} \mathrm{O} \\
(\%)\end{array}$ & $\begin{array}{c}\text { d-excess } \\
(\%)\end{array}$ \\
\hline 1 & $2011 / 03 / 16$ & 74.44 .184 & 95.11 .740 & -32 & snowpack & -256.1 & -33.29 & 10.22 \\
\hline 2 & $2011 / 03 / 18$ & 74.48 .057 & 95.51 .703 & -30 & snowpack & -271.7 & -35.07 & 8.87 \\
\hline 3 & $2011 / 03 / 21$ & 74.52 .674 & 96.37 .207 & -19 & snowpack & -259.2 & -33.64 & 9.90 \\
\hline 4 & $2011 / 03 / 24$ & 74.53 .035 & 97.56 .348 & -22 & new snow & -202.4 & -26.61 & 10.46 \\
\hline 5 & $2011 / 03 / 27$ & 74.47.928 & 99.01 .696 & -20 & new snow & -210.9 & -27.92 & 12.51 \\
\hline 6 & $2011 / 03 / 30$ & 74.32 .409 & 99.20 .652 & -19 & new snow & -198.2 & -26.21 & 11.54 \\
\hline 7 & $2011 / 04 / 04$ & 74.01 .801 & 99.24 .008 & -25 & snowpack & -204.5 & -26.60 & 8.35 \\
\hline 8 & $2011 / 04 / 07$ & 73.40 .243 & 98.55 .290 & -22 & snowpack & -253.3 & -32.75 & 8.72 \\
\hline 9 & $2011 / 04 / 15$ & 72.57 .650 & 96.31 .235 & -20 & snowpack & -277.4 & -35.56 & 7.04 \\
\hline 10 & $2011 / 04 / 16$ & 72.43 .731 & 96.24 .926 & -18 & snowpack & -184.9 & -24.83 & 13.72 \\
\hline 11 & $2011 / 04 / 19$ & 72.01 .364 & 96.25 .583 & -26 & snowpack & -199.1 & -25.94 & 8.40 \\
\hline 12 & $2011 / 04 / 21$ & 71.31 .794 & 96.45 .414 & -25 & snowpack & -257.4 & -32.74 & 4.57 \\
\hline 13 & $2011 / 04 / 23$ & 71.04 .253 & 97.01 .706 & -23 & snowpack & -242.3 & -31.01 & 5.75 \\
\hline 14 & $2011 / 04 / 24$ & 70.50 .366 & 97.08 .161 & -27 & snowpack & -254.2 & -32.55 & 6.16 \\
\hline 15 & $2011 / 04 / 27$ & 70.24 .378 & 97.30 .905 & -20 & snowpack & -254.0 & -32.58 & 6.68 \\
\hline 16 & $2011 / 04 / 28$ & 70.10 .931 & 97.41 .903 & -19 & snowpack & -255.7 & -32.84 & 7.03 \\
\hline 17 & $2011 / 04 / 29$ & 69.58 .100 & 97.51 .284 & -26 & snowpack & -237.9 & -30.71 & 7.81 \\
\hline 18 & $2011 / 04 / 30$ & 69.47.987 & 98.06 .928 & -22 & snowpack & -278.1 & -35.30 & 4.34 \\
\hline 19 & $2011 / 05 / 01$ & 69.37 .832 & 98.18 .105 & -20 & new snow & -244.7 & -31.78 & 9.54 \\
\hline 20 & $2011 / 05 / 02$ & 69.26.251 & 98.38 .122 & -23 & snowpack & -255.1 & -32.43 & 4.39 \\
\hline 21 & $2011 / 05 / 03$ & 69.13.867 & 98.56 .635 & -26 & snowpack & -207.9 & -26.94 & 7.63 \\
\hline 22 & $2011 / 05 / 04$ & 69.02 .487 & 99.09 .891 & -15 & snowpack & -261.9 & -33.71 & 7.79 \\
\hline 23 & $2011 / 05 / 06$ & 68.49 .710 & 98.41 .291 & -18 & snowpack & -266.3 & -33.88 & 4.76 \\
\hline 24 & $2011 / 05 / 07$ & 68.43 .271 & 98.11 .966 & -11 & snowpack & -251.0 & -31.88 & 4.03 \\
\hline 25 & $2011 / 05 / 09$ & 68.31 .349 & 97.22 .316 & -12 & snowpack & -225.9 & -28.75 & 4.05 \\
\hline 26 & $2011 / 05 / 10$ & 68.23 .107 & 97.01 .025 & -12 & snowpack & -206.7 & -26.98 & 9.17 \\
\hline 27 & $2011 / 05 / 12$ & 68.25 .015 & 96.19 .479 & -5 & snowpack & -225.5 & -28.59 & 3.21 \\
\hline
\end{tabular}


で平衡法により分析した。測定誤差は $\delta^{18} \mathrm{O}$ で土 $0.05 \% ， \delta \mathrm{D}$ で士 $0.5 \%$ である。

その他にも，IAEA/GNIP 観測より周辺の Resolute $\left(74.72^{\circ} \mathrm{N}, 85.02^{\circ} \mathrm{W}\right)$ と Hall Beach $\left(68.78^{\circ} \mathrm{N}\right.$, $\left.98.75^{\circ} \mathrm{W}\right)$ に打ける降水の $\delta^{18} \mathrm{O}, \delta \mathrm{D}$ を利用した。 観測期間は 1989 年から 1993 年までと異なるが, 季節は 3 月から 5 月に合わせてデータを抽出した。

\section{3. 結果と考察}

本研究で採取した雪の $\delta^{18} \mathrm{O}$ と d-excess の分布 を Fig. 1 に示す。 $\delta{ }^{18} \mathrm{O}$ は-25\%oから-35\%， d-excess は $3 \%$ から $13 \%$ の範囲にある。 $\delta^{18} \mathrm{O}$ は変動 が大きく顕著な傾向は認められないが, d-excess は $74^{\circ} \mathrm{N}$ より北では $9 \%$ より大きい傾向が認めら れる。また， $\delta^{18} \mathrm{O}$ と地上気温の経時変化を Fig. 2 に示す。 3 月から 4 月中旬までの気温は $-30^{\circ} \mathrm{C}$ か ら $-35^{\circ} \mathrm{C}$ であるが, 4 月中旬以降は徐々に高くなり, 5 月に入ると $-5^{\circ} \mathrm{C}$ まで上昇した。雪の $\delta^{18} \mathrm{O}$ は 3

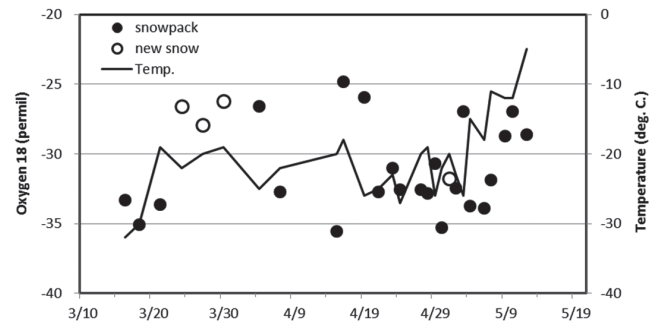

Fig. 2. Temporal variations of $\delta^{18} \mathrm{O}$ in snow and observed surface air temperature.

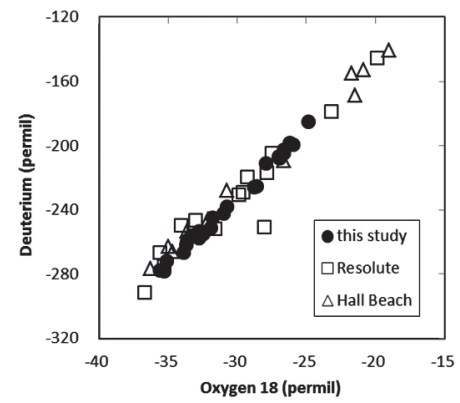

月から 4 月中旬までは - $33 \%$ 以下と $-28 \%$ 以上に分 かれて変動しているが，4月 20 日以降は-30\%o ら-35\%o，5月 9 日以降は-28\%。り大きくなった。 次に，本研究と周辺の IAEA/GNIP 観測地点か ら求めた天水線と, 本研究の $\delta{ }^{18} \mathrm{O}$ と地上気温と の関係を Fig. 3 に示す。本研究で採取した雪の $\delta{ }^{18} \mathrm{O}$ は IAEA/GNIP 観測地点の月平均值（-39\%。 から - $17 \% 0 ）$ の範囲内である。本研究で求めた天 水線は $\delta \mathrm{D}=8.4^{*} \delta{ }^{18} \mathrm{O}+18.7$ であるが, Resolute と Hall Beach はそれぞれ $\delta \mathrm{D}=7.6^{*}{ }^{\circ}{ }^{18} \mathrm{O}+1.2$ と $\delta \mathrm{D}=7.8^{*} \delta^{18} \mathrm{O}+6.6$ である。観測期間が異なるの で単純には比較できないが，天水線の傾きや切片 が大きく違うのは非常に興味深い。これは，北極 圈では気候变動や温暖化の影響を受けやすいた め，観測年によって天水線が大きく変動するのか もしれない。

また, 従来の研究では $\delta^{18} \mathrm{O}$ の年平均值や月平 均值は地上気温とよい相関が認められるが, 本研 究で採取した雪の $\delta^{18} \mathrm{O}$ と地上気温の間には全く 相関が無い $\left(n=27, r^{2}=0.03\right)$ 。この原因としては, 本研究では過去数日間の積雪や新雪を採取してい るため，積雪日の地上気温と一致していないこと が考えられる。また，降雪後にブリザードによつ て摚乱された可能性もある。

さらに $\delta^{18} \mathrm{O}$ の変動要因を考察するため, 観測 地域周辺の大気再解析データ (JCDAS, Onogi et $a l ., 2007)$ の地上気温と，鉛直積分した水蒸気フ ラックスの分布を Fig. 4 に示す。 $\delta^{18} \mathrm{O}$ が $-30 \%$ より小さい時期（3月 16 日から 21 日，4月 7 日

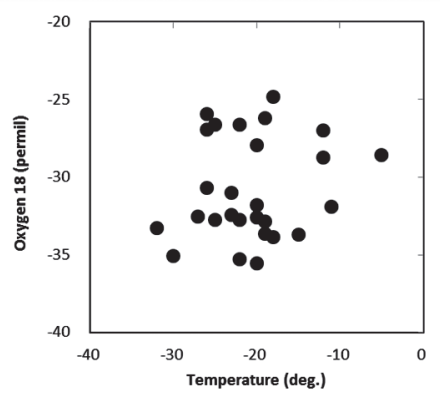

Fig. 3. Relationships between $\delta{ }^{18} \mathrm{O}$ and $\delta \mathrm{D}$ in this study and two IAEA/GNIP stations (left panel) and between surface air temperature and $\delta{ }^{18} \mathrm{O}$ in this study (right panel). 

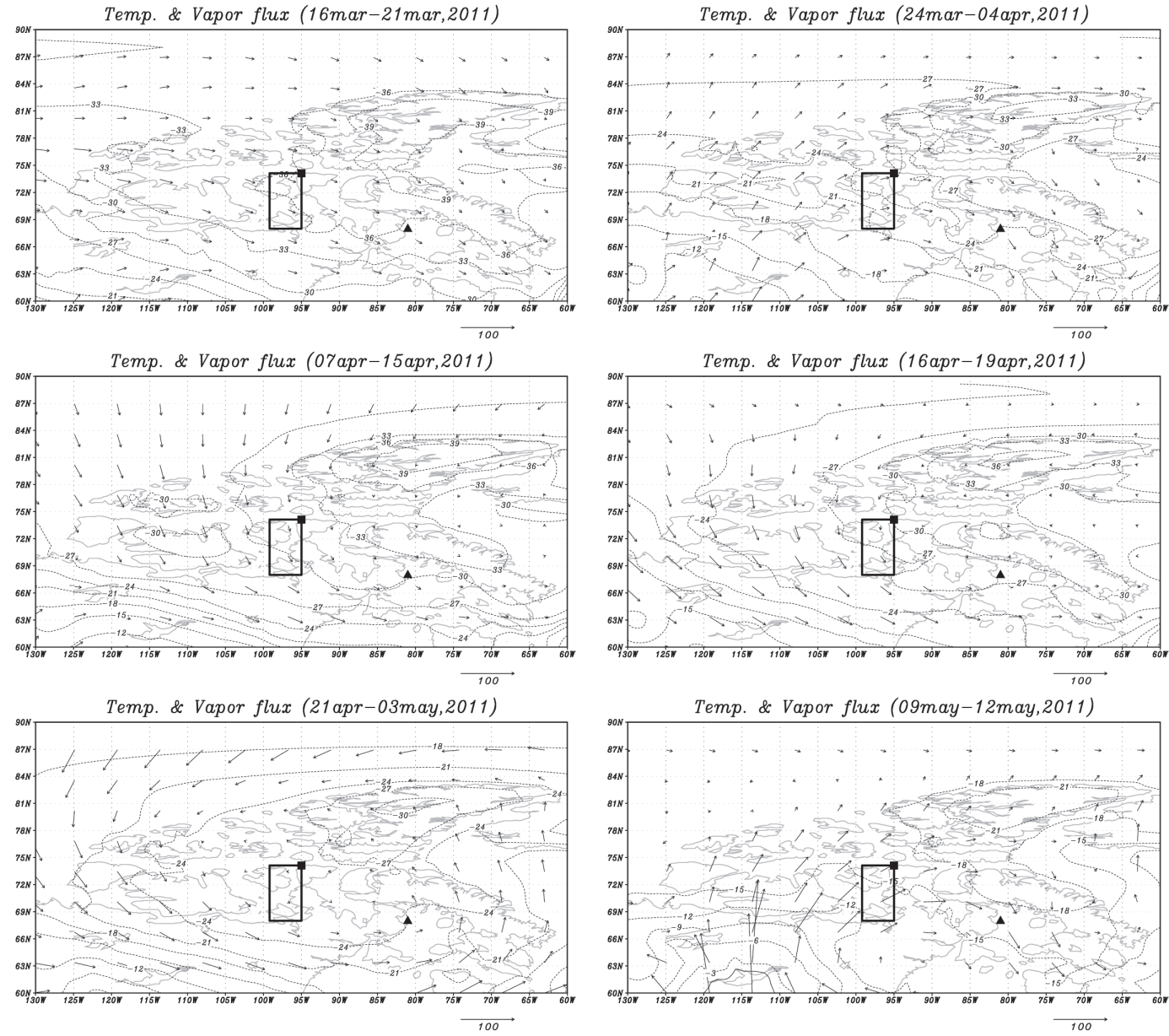

Fig. 4. Distributions of daily surface air temperature (contour, degree Celsius) and water vapor flux (arrow, $\mathrm{kg} / \mathrm{m} / \mathrm{s}$ ) averaged in each observation period by using JCDAS reanalysis. Rectangular, square, and triangle indicate observation field in this study, Resolute and Hall Beach, respectively. Contour interval is $3{ }^{\circ} \mathrm{C}$.

から 15 日，4月 21 日から 5 月 3 日）と大きい時 期 (3月 24 日から 4 月 4 日, 4 月 16 日から 19 日, 5 月 9 日から 12 日）に分けて，その間の気温と 水蒸気フラックスの日平均值を示す。矢の結果, $\delta^{18} \mathrm{O}$ が $-30 \%$ より小さい時期には北または東か らの水蒸気フラックスが卓越しており, 気温は $-30^{\circ} \mathrm{C}$ 程度と低い。反対に， $\delta^{18} \mathrm{O}$ が大きい時期に は南西からの水蒸気フラックスが卓越して打り, 気温は $-25^{\circ} \mathrm{C}$ より高い。しかし，4月 16 日から 19 日だけは $\delta^{18} \mathrm{O}$ は $-25 \%$ 程度と大きいにも関わら ず, 北からの水蒸気フラックスが卓越して打り,
気温は $-28^{\circ} \mathrm{C}$ 程度と低い。

このように，本研究で採取された雪の $\delta^{18} \mathrm{O} の$ 変動は地上気温とは相関が無く, 水蒸気フラック スの卓越方向の影響を受けていることが明らかと なった。北極圈の降水の安定同位体比について, 水蒸気の起源を含めた変動要因や温暖化による影 響など，さらに研究を進める必要がある。

\section{4. まとめ}

カナダ北極海の海水上の雪の安定同位体比の観 
測より，以下の事が明らかとなった。

1. 本研究で採取した雪の $\delta^{18} \mathrm{O}$ は $-25 \%$ から -35\%o，d-excess は 3\%oから 13\%oの範囲にあり， 天水線は $\delta \mathrm{D}=8.4^{*} \delta{ }^{18} \mathrm{O}+18.7$ である。観測期 間は異なるが，周辺の IAEA/GNIP 観測の天 水線とは全く異なる。

2. $\delta{ }^{18} \mathrm{O}$ と地上気温との間には，相関は全く認 められない。この原因としては，過去数日間 の積雪や新雪を採取しているため，積雪日の 地上気温と一致していない，あるいは降雪後 にブリザードによって擋乱された可能性が考 えられる。

3. $\delta{ }^{18} \mathrm{O}$ の変動は水蒸気フラックスの卓越方向 の影響を受けており， $\delta{ }^{18} \mathrm{O}$ が小さい時期に は北または東から， $\delta{ }^{18} \mathrm{O}$ が大きい時期には 南西からの水蒸気フラックスが卓越している。

\section{謝 辞}

利用した大気再解析データセット (JCDAS) は, 気象庁及び電力中央研究所による JRA-25 長期再 解析プロジェクトにより提供されたものである。 北極探検を支援してくださった皆様に感謝致しま す。

\section{引用文献}

Ichiyanagi, K., Numaguti, A., and Kato, K. (2002): Interannual variation of stable isotopes in Antarctic precipitation response to $\mathrm{El} \mathrm{Ni}^{\sim} \mathrm{n}$ oSouthern Oscillation. Geophys. Res. Lett., 29 (1), doi:10.1029/2000GL012815.

Ichiyanagi, K. (2007): Review: Studies and applica- tions of stable isotopes in precipitation. J. Jpn. Assoc. Hydrol. Sci., 37 (4), 165-185.

Miller, G.H., J. Brigham-Grette, R.B. Alley, L. Anderson, H.A. Bauch, M.S.V. Douglas, M.E. Edwards, S.A. Elias, B.P. Finney, J.J. Fitzpatrick, S.V. Funder, T.D. Herbert, L.D. Hinzman, D.S. Kaufman, G.M. MacDonald, L. Polyak, A. Robock, M.C. Serreze, J.P. Smol, R. Spielhagen, J.W.C. White, A.P. Wolfe, E.W. Wolff (2010): Temperature and precipitation history of the Arctic, Quat. Sci. Rev., 29, 1679-1715.

Ogi, M., and J. M. Wallace (2012): The role of summer surface wind anomalies in the summer Arctic sea ice extent in 2010 and 2011, Geophys. Res. Lett., 39, L09704, doi:10.1029/2012GL051330.

Onogi, K., J. Tsutsui, H. Koide, M. Sakamoto, S. Kobayashi, H. Hatsushika, T. Matsumoto, N. Yamazaki, H. Kamahori, K. Takahashi, S. Kadokura, K. Wada, K. Kato, R. Oyama, T. Ose, N. Mannoji and R. Taira (2007): The JRA-25Reanalysis.J. Meteor. Soc. Japan, 85, 369-432.

Rozanski, K., Araguás-Araguás, L., and Gonfiantini, R. (1993): Isotopic patterns in modern global precipitation. In Climate Change in Continental Isotopic Records, Geophys. Monogr. Ser., 78, edited by Swart, P. R., Lohmann, K. C., McKenzie, J., and Savin, S., AGU, Washington D.C., pp. 1-36.

(原稿受付 : 2012年11月27日) (原稿受理 : 2013年 1 月15日)

この論文に対する「討論」を2013年 8 月31日ま で受け付けます。 